\title{
Quality of Postharvest Strawberries: Comparative Effect of Fungal Chitosan Gel, Nanoparticles and Gel Enriched with Edible Nanoparticle Coatings
}

\author{
Natália Ferrão Castelo Branco Melo ${ }^{a^{*}}$, Maria Manuela Estevez Pintado ${ }^{\mathrm{b}}$, \\ José Alberto da Costa Medeiros ${ }^{\mathrm{a}}$, André Galembeck ${ }^{\mathrm{c}}$, Margarida Angélica da \\ Silva Vasconcelos ${ }^{\mathrm{a}}$, Viviane Lansky Xavier $^{\mathrm{a}}$, Marcos Antônio Barbosa de Lima ${ }^{\mathrm{d}}$, \\ TÂnia Lucia Montenegro Stamford ${ }^{\mathrm{a}}$, Thatiana Montenegro Stamford-Arnaud ${ }^{\mathrm{a}}$, \\ Miguel Angel Pelágio Flores ${ }^{\mathrm{c}}$, And Thayza Christina Montenegro Stamford ${ }^{\mathrm{e}}$ \\ ${ }^{a}$ Centro de Ciências da Saúde, Departamento de Nutrição, Universidade Federal de Pernambuco, Av. da \\ Engenharia, s/nํㅜ , Cidade Universitária, 50670-420 Recife, Brazil \\ b Escola Superior de Biotecnologia, Universidade Católica Portuguesa- Porto, Rua Arquitecto Lobão Vital, \\ 4200-375 Porto, Portugal \\ ${ }^{\mathrm{c}}$ Centro de Ciências Exatas e da Natureza, Departamento de Química Fundamental, Universidade Federal de \\ Pernambuco, Av. da Engenharia, s/nํㅡ, Cidade Universitária, 50670-420 Recife, Brazil \\ d Departamento de Biologia, Universidade Federal Rural de Pernambuco, Rua Manuel de Medeiros, 97, Dois \\ Irmãos, 52171-900 Recife, Brazil \\ ${ }^{\text {e }}$ Centro de Ciências Médicas, Departamento de Microbiologia Universidade Federal de Pernambuco, Av. da \\ Engenharia, s/nº, $2^{\underline{o}}$ andar, Microbiologia e Imunologia, Cidade Universitária, CEP: 50.670-420, Recife, PE, \\ Brazil \\ ${ }^{*}$ Corresponding author \\ natalia_melo_835@hotmail.com \\ TEL: $+55-81-988013648$ \\ FAX: $+55-81-21268473$
}

Received: 12 December 2019; Published online: 18 October 2020

\begin{abstract}
This study compared, for the first time, the postharvest conservative action of edible fungal chitosan coatings (gel, nanoparticles and gel-nanoparticle) on the physico-chemical, sensorial and microbiological characteristics of strawberries. The nanoparticles were prepared by an ionic gelation method and characterized by dynamic light scattering and scanning electron microscopy. The antioxidant (DPPH* and ABTS*) activity of the edible coatings and the antimicrobial (macrodilution method) action against phytopathogenic fungi were verified. The nanoparticles had a size of $331.1 \mathrm{~nm}$ and a zeta potential of + $34 \mathrm{mV}$. The gel, nanoparticles and gel+nanoparticles exhibited minimum inhibitory concentration values ranging from 4 to $5,1.5$ to 2.5 and $1.0+0.5$ to $2.0+1.5$ g. $\mathrm{L}^{-1}$, respectively. All the edible coatings exhibited antifungal action. All the coatings had high scavenging activity, especially the gel edible coating. The coatings, especially the gel+nanoparticles, decreased the weight loss, microbiological growth, soluble solids, maturity index and moisture loss of the strawberry and preserved the $\mathrm{pH}$ values, anthocyanin content, titratable acidity and sensory characteristics. Therefore, the use of chitosan edible coating containing nanoparticles can be a promising strategy to improve the post-harvest quality of strawberries.
\end{abstract}

Keywords: Antifungal activity; Antioxidant activity; Biopolymer; Nanotechnology; Shelf-life 


\section{Introduction}

Strawberry (Fragaria $\times$ ananassa Duch. $)$ is a non-climateric fruit cultivated worldwide and characterized by an attractive taste, flavour and important nutritional compounds. However, due to its high respiration rate, excessive soft texture, water loss and microbiological decay, strawberries are considered highly perishable fruit (postharvest life approx. 3$4 \mathrm{~d}$ at $20{ }^{\circ} \mathrm{C}$ ) (Shahbazi, 2018). So, various technologies have been developed for strawberry preservation in accordance with the principles of green chemistry (Dhital et al., 2017; Oregel-Zamudio, Angoa-Pérez, Oyoque-Salcedo, Aguilar-González, \& Mena-Violante, 2017).

The application of edible coating has been considered as an alternative method to prevent fruit postharvest decay and to extend the storage life, while retaining the overall quality of different fresh commodities (Yousuf, Qadri, \& Srivastava, 2018). Different biological materials have been used to prepare packaging materials, especially chitosan. This polymer is traditionally obtained from crustacean shells. However, fungi biomass is a promising eco-friendly alternative for obtaining chitosan because it is not affected by seasonal factors, can be produced on a large scale without changing the physicochemical characteristics of the polymer and does not contain any of the proteins that induce allergic reactions to crustaceans (Berger et al., 2018).

Chitosan has received much interest for its application in food preservation because of its excellent film-forming ability, antimicrobial and antioxidant activities, biocompatibility, biodegradability and non-toxicity (Muzzarelli et al., 2012). Nevertheless, it is believed that the characteristics of edible coatings can be improved by incorporating nanostructures into the polymer matrix (Pilon et al., 2015). According to Eshghi et al. (2014), nanotechnology could facilitate the development of novel packaging materials and nonpolluting, cheaper, and more efficient packaging techniques.

Unique physicochemical characteristics are consequences of a reduction in particle size and increasing the surface to particle size ratio in nanoparticles. Due to the interaction between nanoparticles and chitosan gel, the chitosan edi- ble composite coatings are supposed to show enhanced antimicrobial activity and barrier properties to the internal gas atmosphere of the fruit, which gives better maintenance of the physicochemical and microbiological characteristics of fresh strawberry (Eshghi et al., 2014).

However, until now, no research has demonstrated that the use of chitosan nanoparticle alone in the edible coating is actually a better fruit preservative than the use of chitosan gel edible coating or coating composed with gel enriched with chitosan nanoparticles. Therefore, the aim of this research was to compare, for the first time, the preservative action of three different fungal chitosan edible coatings (gel, nanoparticles and gel enriched with nanoparticles) on the quality of postharvest strawberries during storage time.

\section{Materials and Methods}

\section{$2.1 \quad$ Materials}

Strawberries were purchased from Supplies and Service Company of Pernambuco (Recife, Brazil) and selected according to size and colour; they showed no signs of deterioration or mechanical damage. The chitosan (KiOnutrime ${ }^{\circledR}$ ) was provided by the Kitozyme ${ }^{\circledR}$ Company (Herstal, Belgium) and it is a fungal chitosan (deacetylation degree of $86 \%$, molecular weight of $4 \times 10^{3} \mathrm{Da}$ ), extracted from Aspergillus niger mycelium. The other substances used were obtained from commercial sources.

\section{$2.2 \quad$ Preparation and characterization of chitosan nanoparticles}

The fungal chitosan nanoparticles (FCN) were prepared by an ionic gelation method with some modification (Calvo, RemunanLopez, VilaJato, \& Alonso, 1997). The chitosan (CS) solution, at a concentration of 2 g. $\mathrm{L}^{-1}$, was prepared by dissolving the polymer in $24 \mathrm{~mL}$ of $\mathrm{pH} 4$ solution (1 $\%$ acetic acid $+1 \% \mathrm{NaOH})$ and stirred for 30 min. The sodium polyphosphate (TPP) solution was dissolved in deionized water at concentration of 1 g.L $\mathrm{L}^{-1}$. Then, $6 \mathrm{~mL}$ of TPP solution 
was gradually dropped $\left(0.2 \mathrm{~mL} \cdot \mathrm{min}^{-1}\right)$ into 24 $\mathrm{mL}$ of chitosan solution using a peristaltic pump (Atlas Syringe Pump) under vigorous magnetic stirring at room temperature. The final ratio of CS:TPP was 4:1. Once the dropwise addition was completed, the nanoparticle suspension was stirred for an additional $1 \mathrm{~h}$.

The morphology and particle size of the FCN were characterized by scanning electron microscopy (SEM) (SEM Quanta 200 FEI). The freeze-dried nanoparticles were mounted on a specimen stub (with carbon ribbon and silver ink) (Taab, Berkshire, UK) and the sample was coated with a $10 \mathrm{~nm}$ thick gold film using a sputter coater. Nanoparticle morphology was observed using an electron acceleration voltage of $20 \mathrm{kV}$. The zeta potential of the nanoparticles was measured using a Malvern Zetasizer (model Nano ZS90, Malvern, UK). The analysis was performed at a scattering angle of $90^{\circ}$ at $25^{\circ} \mathrm{C}$ and $633 \mathrm{~nm}$.

The size of the FCN was analyzed by Dynamic Light Scattering system (Zetasizer Nano ZS90, Malvern Instruments, UK) $\left(633 \mathrm{~nm}, 90^{\circ}, 25^{\circ} \mathrm{C}\right)$ (Tsai, Chen, Bai, \& Chen, 2011).

\subsection{Determination of the antifungal activity}

The three forms of fungal chitosan (nanoparticles, gel and gel enriched with nanoparticles) were used in the broth macrodilution technique to determine the minimum inhibitory concentration (MIC) against strawberry phytopathogenic fungi (Botrytis cinerea URM 2802, Rhizopus stolonifera URM 3728 and Aspergillus niger URM 7282). For this assay, phytopathogenic fungi stock cultures were subcultured in Sabouraud agar at $28{ }^{\circ} \mathrm{C}$ for 7 days to allow sufficient sporulation. The fungal spores were collected in a sterile saline solution (0.85 g. $\left.(100 \mathrm{~mL})^{-1} \mathrm{NaCl}\right)$ in fungal growth medium, and the suspension was filtered through a sterile triple-gauze layer to retain hyphal fragments. The number of spores present in the suspension was determined with a haemocytometer. The spore concentration obtained was adjusted with sterile saline solution to provide a fungal inoculum of approximately $10^{6}$ spores. $\mathrm{mL}^{-1}$ (Vascon- celos de Oliveira et al., 2014a).

The broth macrodilution technique was performed in triplicate. Initially, $0.5 \mathrm{~mL}$ of a suspension of the phytopathogenic fungi was inoculated, separately, into $2 \mathrm{~mL}$ of Sabouraud broth (with the concentration adjusted to $5 \mathrm{~mL}$ ), and $2.5 \mathrm{~mL}$ of the solutions containing different concentrations of test substances were added. The mixture was incubated at $25{ }^{\circ} \mathrm{C}$ for 7 days, and at the end of the incubation period, the lowest concentration of test substances that exhibited no visible fungal growth was considered to be the MIC (Sharma \& Tripathi, 2008). This assay was performed separately for each test substance and fungi strains.

For this assay, the freeze-dried FCN and the CS were diluted in a solution of $1 \%$ acetic acid and $\mathrm{pH}$ was adjusted to 5.8 with $1 \% \mathrm{NaOH}$. The solution of $1 \%$ acetic acid with $\mathrm{pH}$ adjusted to 5.8 was tested, separately, as a control and exhibited no inhibitory effects against the phytopathogenic fungi.

\subsection{Comparative antioxidant activity}

The antioxidant activity of the fungal CS gel, FCN and CS gel enriched with FCN was evaluated using DPPH (2,2-diphenyl-1picrylhydrazyl) free radical scavenging assay and ABTS (2,2'-azino-bis-3-ethylbenzthiazoline6-sulphonic acid) assay.

\section{DPPH radical scavenging ability}

The comparative scavenging effect of test substances on DPPH radicals was measured according to the method described by Chen et al. (2015). $2.5 \mathrm{~mL}$ of the solutions of the test substances at different concentrations (MIC/2, $\mathrm{MIC}$ and $2 \mathrm{xMIC}$ ) were added into $2.5 \mathrm{~mL}$ of freshly prepared DPPH solution in ethanol (50 g. $\left.\mathrm{L}^{-1}\right)$. The mixture was shaken thoroughly with a vortex mixer and incubated for $30 \mathrm{~min}$ at 33 ${ }^{\circ} \mathrm{C}$. Then, the absorbance was measured at 517 nm using a UV-vis spectrophotometer (Agilent, USA). The percentage of DPPH radical scav- 
enged was calculated as follows:

$$
\operatorname{DPPH}(\%)=\left(1-\left(A a-\frac{A b}{A c}\right)\right) \times 100
$$

where $A a=$ absorbance of the sample mixed with DPPH solution, $A b=$ absorbance of the sample without DPPH solution and $A c=$ absorbance of blank control without sample.

\section{ABTS radical scavenging ability}

The analysis of ABTS scavenging activity was determined according to the method described by Larrauri, Ruperez, and SauraCalixto (1997). In this method, ABTS was prepared by mixing $5 \mathrm{~mL}$ of ABTS solution $(7.9 \mathrm{mM})$ with $88 \mu \mathrm{L}$ of potassium persulfate $\left(\mathrm{K}_{2} \mathrm{~S}_{2} \mathrm{O}_{8}\right)$ solution (140 $\mathrm{mM})$. This mixture was allowed to stand for $16 \mathrm{~h}$ at room temperature in the dark until reaching a stable oxidative level. Then, $1 \mathrm{~mL}$ of ABTS solution was diluted in ethanol to given an absorbance of $0.700 \pm 0.05 \mathrm{~nm}$ at $734 \mathrm{~nm}$. In a dark place, $3 \mathrm{~mL}$ of ABTS solution was added to $30 \mu \mathrm{L}$ of test substances at different concentrations (MIC/2, MIC and 2xMIC). After $6 \mathrm{~min}$, the absorbance was taken at $734 \mathrm{~nm}$ using the spectrophotometer (Agilent, USA). The scavenging capability of test substances was calculated using following equation:

$$
A B T S(\%)=\left(1-\left(A a-\frac{A b}{A c}\right)\right) \times 100
$$

where $A c=$ absorbance of a control (blank) lacking any radical scavenger and $A a=$ absorbance of the remaining ABTS in the presence of scavenger, $A b=$ absorbance of the sample without ABTS.

\subsection{Preparation and application of edible coatings on strawberries}

The strawberries were immersed in sodium hypochlorite $(1 \%)$ for $15 \mathrm{~min}$, washed with potable water and left to dry $(2 \mathrm{~h})$. Then, the strawberries were immersed $(1 \mathrm{~min})$ in the coating solutions and left to dry (30 min) on a nylon filter to drain the excess liquid (Vasconcelos de
Oliveira et al., 2014a).

The strawberries were divided into five groups. One group was the negative control (without edible coating), the other group was the positive control (fruit coated with glycerol - $2.5 \mathrm{~mL}$.(100 $\mathrm{mL})^{-1}$ ) and the other three groups were coated with CS gel, FCN and CS gel enriched with FCN. For the formation of the different fungal chitosan edible coatings, we used the highest MIC value determined for the strawberries phytopathogenic fungi. The pure chitosan or lyophilized nanoparticles were diluted in $1 \%$ acetic acid and the $\mathrm{pH}$ was adjusted to 5.8 (Vasconcelos de Oliveira et al., 2014a).

Each treatment included 40 strawberries that were stored for 6 days at room temperature $(25$ $\pm 2{ }^{\circ} \mathrm{C}$ ) and 12 days at cold temperature (10 $\pm 2{ }^{\circ} \mathrm{C}$ ) (Shahbazi, 2018). These temperatures were chosen based on the methodologies used by Dantas Guerra et al. (2015), dos Santos et al. (2012), Gol, Patel, and Rao (2013), Vasconcelos de Oliveira et al. (2014a, 2014b) and Castelo Branco Melo et al. (2018).

\subsection{Physicochemical analysis on strawberries}

The strawberries were evaluated every 3 days for general quality parameters such as moisture content, total soluble solids (TSS), titratable acidity (TA), maturity index (MI), pH and anthocyanin content. The day of the application of the edible coatings was considered time zero (day zero) in the storage period.

The TSS content was determined with a refractometer (Model AUS JENA, Germany), and the results were expressed as \% TSS (AOAC, 932.12). The AT was determined by titrating with 0.1 mol. $\mathrm{L}^{-1} \mathrm{NaOH}$ to $\mathrm{pH} 8.2$, and the results were expressed as a percentage of citric acid (AOAC 920.149). The MI was calculated as the quotient of soluble solids and acidity. The $\mathrm{pH}$ of the fruit samples was assessed using a digital pH meter (Model: Micronal B474) according to the standard method described in AOAC (2012) (AOAC 981.12). The moisture content was determined by dehydration of the fruit $\left(70{ }^{\circ} \mathrm{C} / 24\right.$ h) until the dry weight was obtained, and the weight losses were expressed as a percentage of 
the intitial weight (AOAC 934.06). The anthocyanin content was estimated by the method described by Lees and Francis (1972). The results were expressed in $\mathrm{g} . \mathrm{L}^{-1}$.

\subsection{Weight loss percentage}

The weight loss was considered the difference between the initial and final weight of coated and uncoated strawberries. The results were expressed as the percentage loss from the initial weight, according to the method described by Gol et al. (2013).

\subsection{Decay rate of strawberries}

The strawberries were examined for any microorganism infection during storage. The decay percentage of coated and uncoated fruit was calculated as the number of decayed fruit divided by the initial number of all strawberries multiplied by 100 (Castelo Branco Melo et al., 2018).

\subsection{Sensory evaluation}

The sensory analyses were performed after approval by an Ethics Research Committee - Certificate Number: 58937016.3.0000.5208. Uncoated and coated strawberries at the same concentration used in the physicochemical analysis, were stored at a cold temperature. Sensory attributes of the strawberries were analysed 3 days after the coating application in a standardized testing room in the sensory laboratory of the Department of Nutrition located in Federal University of Pernambuco (Brazil).

Each sample was presented simultaneously in dishes coded with 3-digit random numbers to each panellist for evaluation three days after the coating application. The panellists were asked to drink water and eat a salty biscuit between samples. In the preference test, the tasters were asked to choose the most and least appreciated samples based on their overall evaluation. The intent to purchase was assessed on a five-point structure hedonic scale ranging from one (certainly would not by) to five (certainly would buy). For the acceptability test, a nine-point structured hedonic scale was used, ranging from one (dislike very much) to nine (like very much) (Castelo Branco Melo et al., 2018).

\subsection{Sensory evaluation}

All data were analysed by analysis of variance (ANOVA) using Origin 8.0 software. ANOVA was followed by a post hoc Tukey's test. This test was performed to determine differences $(\mathrm{p}<$ 0.05 ) between the results.

\section{Results and discussion}

\subsection{Characterization of FCN}

The Figure 1 shows that FCN presented $331.1 \pm$ $7.21 \mathrm{~nm}$. Based on previous studies, this particle size contributes to the performance of FCN as antifungal agent. This effect can be seen in the research of Saharan et al. (2015) and Xing et al. (2016), which produced particles with an average size of $374.3 \mathrm{~nm}$ and $296.96 \mathrm{~nm}$, respectively, for use as an antimicrobial agent against phytopathogenic fungi. According to MubarakAli et al. (2018), chitosan nanoparticles present antifungal activity due to their large surface area. It allows them to fix on a large number of fungi, which contributes to their use as an edible coating.

FCN also had a narrow size distribution with a polydispersity index of 0.377 . Generally, the use of low molecular weight chitosan produces small and uniform nanoparticles (Paomephan et al., 2018), as was seen in our FCN. According to Saharan et al. (2015), this size uniformity also contributes to the antifungal activity of chitosan nanoparticles. Therefore, the particles produced in the present research exhibited an average size which contributed to the antifungal activity and consequently to the ability of these particles to preserve the quality of postharvest fruit as an edible coating. Furthermore, the FCN produced, according to Severino et al. (2012), will not be absorbed by the human intestinal epithelium when people eat a fruit with an edible coating containing FCN. These authors reported that particles $>300 \mathrm{~nm}$ are not absorbed by the human intestinal epithelium.

The morphological characterization of FCN by

\begin{tabular}{l|l|l|l} 
IJFS | October 2020 | Volume 9 & pages 373-393
\end{tabular} 
the SEM confirmed the uniform spherical shape of the particles (Fig. 1). However, SEM analysis showed the formation of aggregates between the particles. Fan, Yan, Xu, and Ni (2012) reported that the formation of these aggregates is caused by the hydrogen bonds between the particles formed during the drying process of the sample for SEM analysis.

The FCN observed by SEM exhibited a smaller size than the size of FCN analyzed by dynamic light scattering. It could have occurred because the DLS technique observes the state of the sample in the presence of solvent associated with the particles, while SEM gives the size of the particles in dry form (Kiilll et al., 2017).

The zeta potential of FCN was $+34 \mathrm{mV}$, which meant that these nanoparticles could be stable for a long time. This is in agreement with the results of Sullivan et al. (2018) who reported that when chitosan and TPP are mixed with each other, they spontaneously formed complexes with an overall positive surface charge. According to Yien, Zin, Sarwar, and Katas (2012), nanoparticles with a surface charge greater than $+30 \mathrm{mV}$ are more stable. Furthermore, Saharan et al. (2015) reported that particles with a positive surface charge exhibit a higher affinity towards biological membranes in an aqueous environment and, therefore, more antifungal activity.

\subsection{Determination of the antifungal activity}

The MIC results are shown in Table 1 . These results were in agreement with Verlee, Mincke, and Stevens (2017) who showed that the MIC values of chitosan against fungi ranges from 0.01 g. $\mathrm{L}^{-1}$ to 7.75 g.L ${ }^{-1}$. Furthermore, the MIC values found in our research were lower than the values found by dos Santos et al. (2012) and Dantas Guerra et al. (2015) when they analysed the MIC values of chitosan from shrimp against $A$. niger, B. cinerea and R. stolonifera. However, the different MIC values found in our research could not be related to microbiological origin of the chitosan used. Vasconcelos de Oliveira et al. (2014a) and Vasconcelos de Oliveira et al. (2014b) also used fungal chitosan against phy- topathogenic fungi and found $\mathrm{MIC}=15$ g. $\mathrm{L}^{-1}$ for $B$. cinerea and $\mathrm{MIC}=7.5$ g. $\mathrm{L}^{-1}$ for $A$. niger and $R$. stolonifera. It was suggested that the difference between the chitosan MIC values against the same species of fungi could be related to the physicochemical characteristics of the polymer, such as the degree of deacetylation and molecular weight (Verlee et al., 2017).

According to Badawy and Rabea (2011), low molecular weight chitosan presents a better antifungal activity. This occurs due to the ability of this polymer to penetrate in the fungal cell wall. This suggests that the main target of action of the low molecular weight chitosan is the plasma membrane of the fungi (Park et al., 2008). The fungal chitosan used in the present research had a low molecular weight, which could have contributed to the high antifungal activity and low MIC values.

In addition, Kong, Chen, Xing, and Park (2010) reported that the chitosan presents a polycationic structure due to the presence of amino groups in the polymer chain. These groups give the polymer a high density of positive charges that could be measured by the degree of deacetylation. Therefore, a chitosan with a high degree of deacetylation exhibited better electrostatic interaction with the fungal cell wall. In general, the antifungal activity increases when the degree of deacetylation is higher and the molecular weight is lower (Verlee et al., 2017).

Despite the discrepancies between the physicochemical characteristics of chitosan, it is known that chitosan can affect the fungal cell membrane via electrostatic interactions with the negatively charged phospholipids. Once the cell membrane is disrupted, chitosan is capable of entering the cell. This could lead to inhibition of DNA/RNA synthesis and disruption of protein synthesis (Ma, Garrido-Maestu, \& Jeong, 2017). FCN improved the antifungal activity when compared to CS gel. According to Kheiri, Jorf, Malihipour, Saremi, and Nikkhah (2016), chitosan nanoparticles exhibit higher antifungal activity than CS gel on account of the special characteristics (size and surface charge) of these particles. The negatively charged surface of the fungal cell is the target site of the polycation. Therefore, the polycationic FCN with higher surface charge density interacts with the fungus to a greater de- 

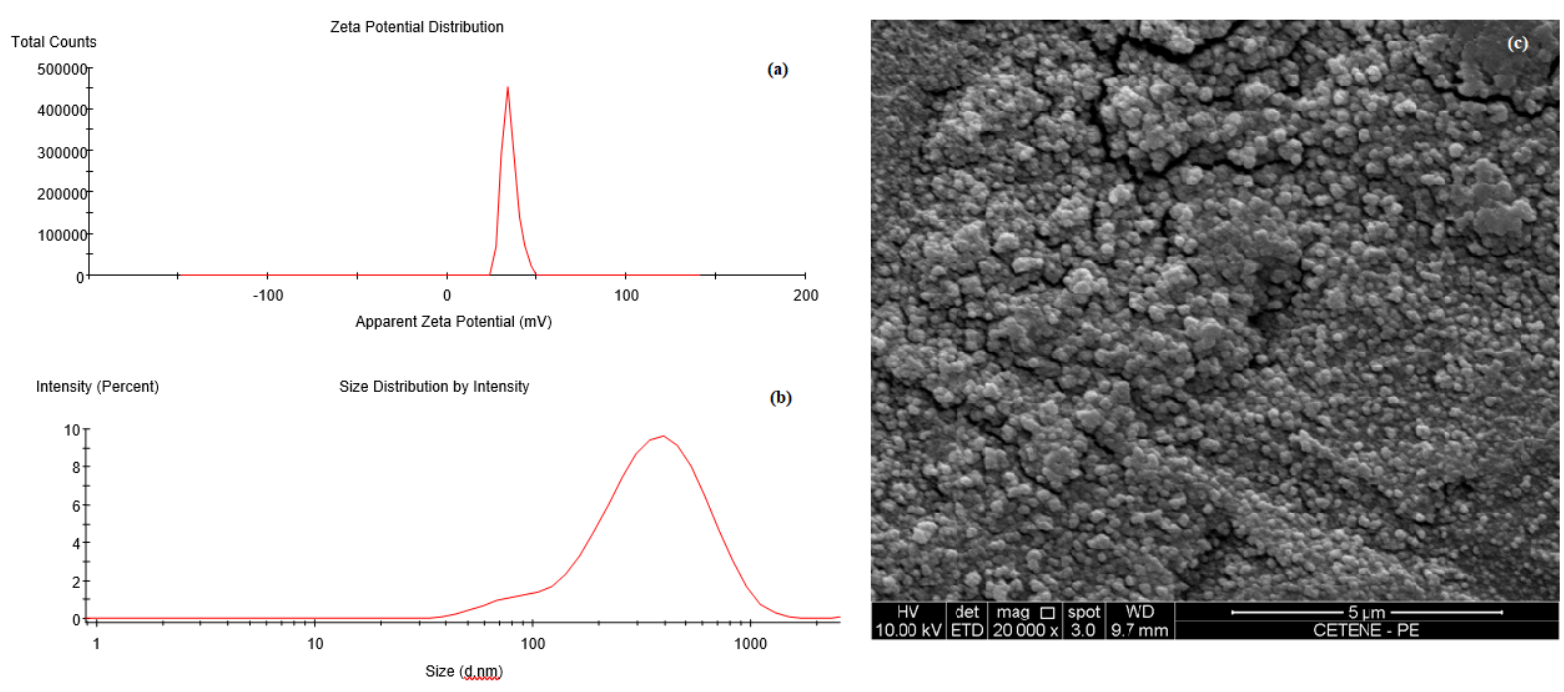

Figure 1: Zeta potential (a), average size distribution (b) and SEM image (c) of fungal chitosan nanoparticles

gree than CS itself (Kheiri et al., 2016). Due to the larger surface area of the nanoparticles, FCN could be tightly adsorbed onto the surface of the fungal cells so as to disrupt the membrane, which would lead to the leakage of cellular contents, thus killing the fungal cells (Garcia-Rincon et al., 2010). Chitosan nanoparticles penetrate into fungal cells and tightly bind nucleic acids via electrostatic interaction between cationic FCN and anionic DNA. This suggests that they may cause a variety of damage and selective inhibition such as inactivation of the synthesis of essential mRNA encoded by various genes required for important metabolic and infectious processes of the microorganism (Yien et al., 2012).

The MIC values for $A$. niger were higher than the values found for the other fungi for all test substances. Yien et al. (2012) found a similar result. This fungus, in particular, was found to be highly resistant to chitosan, because $A$. niger contains $10 \%$ of chitin in the cell wall, and fungi that have chitosan as one of their cell wall components are more resistant to externally applied chitosan and consequently more resistant to chitosan nanoparticles (Allan, Allan, \& Hadwiger, 1979).

When the CS gel was enriched with FCN an improvement was observed in the antifungal activ- ity. The mixture of the gel with FCN presented the best inhibitory effect against the strawberry phytopathogenic fungi. This suggests that when the gel and nanoparticles were together, they improved their individual antifungal activity. According to Lee, Song, and Lee (2010), when chitosan nanoparticles are well-dispersed in the solution they are more efficiently transported to the cell wall, which causes metabolic disorders and leads to increased antimicrobial activity.

\subsection{Antioxidant activity}

As is shown in Figure 2a, the test substances showed strong activity to scavenging the DPPH free radicals in a dose-dependent manner. Similar results were found by Chen et al. (2015) and MubarakAli et al. (2018). The same behaviour was found in the ABTS assay (Fig. 2b). DPPH radicals are less reactive than ABTS radicals. Unlike the reactions with DPPH radicals, which involve $\mathrm{H}$-ion transfer, the reactions with ABTS radicals involve an electron-transfer process (Chen et al., 2015).

In DPPH assay, any test substance at the concentration of $\mathrm{MIC} / 2$ showed no scavenging effect. The scavenging effect occurred only when 
Table 1: Antifungal activity of chitosan gel (CS gel), fungal chitosan nanoparticles (FCN) and gel enriched with nanoparticles (CS Gel + FCN) against strawberry phytopathogenic fungi.

\begin{tabular}{lccc}
\hline \multirow{2}{*}{ Test Substance } & \multicolumn{3}{c}{ Phytopathogenic fungi } \\
\cline { 2 - 4 } & $\begin{array}{l}\text { R. stolonifer (URM 3728) } \\
\text { g.L. } \text { B. cinerea (URM 2802) }^{-1}\end{array}$ & $\begin{array}{c}\text { A. niger (URM 7282) } \\
\text { g. } \text { - }^{-1}\end{array}$ \\
\hline CS gel & 4.0 & 4.0 & g.L \\
FCN & 1.5 & 1.5 & 5.0 \\
CS gel + FCN & $1.0+0.5$ & $1.0+0.5$ & 2.5 \\
\hline
\end{tabular}

Note: Values represent the mean of three replicates.

The standard deviation was zero for all mean values.

the test substances were used at the MIC and $2 \mathrm{MIC}$ concentrations. However, at a low concentration $(\mathrm{CIM} / 2)$, the scavenging ability of the test substances on ABTS was stronger than with DPPH radicals.

The scavenging ability of CS gel on DPPH and ABTS was stronger than FCN and CS gel enriched with FCN. It may have been due to the presence of the amino groups in the CS chain (Siripatrawan \& Harte, 2010). According to Yen, Yang, and Mau (2008), the scavenging mechanism of chitosan is related to the fact that free radicals can react with the residual free amino $\left(\mathrm{NH}_{2}\right)$ groups to form a stable macromolecule radical, and the $\mathrm{NH}_{2}$ can form ammonium $\left(\mathrm{NH}_{3}^{+}\right)$groups by absorbing a hydrogen ion from the solution. Therefore, chitosan with higher degree of deacetylation will probably exhibit a strong antioxidant activity.

The FCN presented the lowest antioxidant activity for both tests. This could be due to the lower number of free amino groups present in the nanoparticles. During the ionic gelation method, the process of the nanoparticles synthesis, the amino groups of the chitosan chain bind to TPP to form the FCN (Bugnicourt, Alcouffe, \& Ladavière, 2014). Therefore, the fungal chitosan nanoparticles have fewer free NH2 groups than CS gel. It contributed to the lower FCN antioxidant activity, because these free amino groups are responsible for binding to free radicals.

It is important to note that the MIC concentrations of FCN (2.5 g.L $\left.{ }^{-1}\right)$ is half of the MIC concentration of CS gel $\left(5 \mathrm{~g} . \mathrm{L}^{-1}\right)$. This suggests that the FCN had a lower antioxidant activity than the CS gel not only due to the smaller number of free amino groups, but also to its lower MIC value that were used in the DPPH and ABTS assays.

However, when FCN was dispersed in the CS gel an improvement in their scavenging ability occured. It could be seen in the ABTS assay when the CS gel and CS gel enriched with FCN was tested in 2MIC concentration. These substances exhibited similar scavenging effect at this concentration $(p>0.05)$. This result suggested that when CS gel was mixed with FCN was an increase not only their antifungal activity, but also an improvment in the antioxidant activity of this mixture.

\subsection{Effects on physicochemical characteristics of strawberries}

The physicochemical changes in uncoated and coated strawberries were evaluated throughout storage at room temperature and under refrigeration for 6 and 12 days, respectively (Tables 2 and 3). According to Oregel-Zamudio et al. (2017), the soluble solids content during the ripening of strawberries should range from $4.6 \%$ to $11.9 \%$. In the present research, all fruit samples presented soluble solids content in the range recommended. However, at the end of the storage period at both temperatures, the control sample exhibited significantly higher soluble solids content $(\mathrm{p}<0.05)$ than the chitosan-based edible coatings. This result suggested that the control fruit continued to have active metabolism, which contributed to the conversion of the starch to acid 
Strawberries coated with fungal chitosan (gel, nanoparticles, gel + nanoparticles) 381

Table 2: Mean values of physicochemical quality parameters in strawberries stored at room temperature for 6 days in the absence of edible coating (control) and with glycerol, chitosan gel (CS Gel), fungal chitosan nanoparticles (FCN) and chitosan gel enriched with fungal chitosan nanoparticles (Gel + FCN).

\begin{tabular}{|c|c|c|c|}
\hline \multirow[b]{2}{*}{ Treatments } & \multicolumn{3}{|c|}{ Days of storage } \\
\hline & 0 & 3 & 6 \\
\hline \multicolumn{4}{|c|}{ Soluble solids $(\%)$} \\
\hline Control & $8.00( \pm 0.02)^{A a}$ & $8.27( \pm 0.23)^{A a}$ & $8.27( \pm 0.23)^{A a}$ \\
\hline Glycerol & $8.20( \pm 0.02)^{A a}$ & $7.20( \pm 0.00)^{B b}$ & $8.10( \pm 0.00)^{A a}$ \\
\hline CS Gel & $8.46( \pm 0.58)^{A a}$ & $7.17( \pm 0.06)^{B b}$ & $7.20( \pm 0.00)^{B b}$ \\
\hline FCN & $8.13( \pm 0.12)^{A a}$ & $7.20( \pm 0.00)^{B b}$ & $6.93( \pm 0.46)^{B b}$ \\
\hline $\mathrm{Gel}+\mathrm{FCN}$ & $8.03( \pm 0.06)^{A a}$ & $7.20( \pm 0.00)^{B b}$ & $7.20( \pm 0.00)^{B b}$ \\
\hline \multicolumn{4}{|c|}{ Titratable acidity (\% citric acid) } \\
\hline Control & $1.15( \pm 0.01)^{A a}$ & $0.88( \pm 1.13)^{A b}$ & $1.04( \pm 0.02)^{A a}$ \\
\hline Glycerol & $1.07( \pm 0.08)^{A a b}$ & $1.16( \pm 0.05)^{A a}$ & $1.18( \pm 0.02)^{A a}$ \\
\hline CS Gel & $1.00( \pm 0.01)^{B a b}$ & $1.06( \pm 0.01)^{A a b}$ & $1.10( \pm 0.01)^{A a}$ \\
\hline $\mathrm{FCN}$ & $1.06( \pm 0.00)^{B a b}$ & $1.18( \pm 0.03)^{A a}$ & $1.12( \pm 0.04)^{A B a}$ \\
\hline $\mathrm{Gel}+\mathrm{FCN}$ & $0.98( \pm 0.01)^{A b}$ & $1.11( \pm 0.03)^{A a b}$ & $1.18( \pm .11)^{A a}$ \\
\hline \multicolumn{4}{|c|}{ Maturity index } \\
\hline Control & $7.04( \pm 0.04)^{A a}$ & $9.38( \pm 1.04)^{A a}$ & $8.12( \pm 0.16)^{A a}$ \\
\hline Glycerol & $7.59( \pm 0.74)^{A a}$ & $6.24( \pm 0.26)^{A b}$ & $6.89( \pm 0.13)^{A a b}$ \\
\hline CS Gel & $8.29( \pm 0.59)^{A a}$ & $6.82( \pm 0.04)^{B b}$ & $6.54( \pm 0.08)^{B b}$ \\
\hline FCN & $7.64( \pm 0.13)^{A a}$ & $6.10( \pm 0.14)^{B b}$ & $6.03( \pm 0.32)^{B b}$ \\
\hline $\mathrm{Gel}+\mathrm{FCN}$ & $8.20( \pm 0.06)^{A a}$ & $6.48( \pm 0.16)^{B b}$ & $6.12( \pm 0.59)^{B b}$ \\
\hline \multicolumn{4}{|l|}{$\mathrm{pH}$} \\
\hline Control & $3.58( \pm 0.02)^{A a}$ & $3.49( \pm 0.02)^{B b}$ & $3.05( \pm 0.00)^{C b}$ \\
\hline Glycerol & $3.41( \pm 0.01)^{A c}$ & $3.42( \pm 0.02)^{A c}$ & $3.06( \pm 0.08)^{B b}$ \\
\hline CS Gel & $3.49( \pm 0.01)^{A b}$ & $3.52( \pm 0.02)^{A b}$ & $3.45( \pm 0.01)^{B a b}$ \\
\hline $\mathrm{FCN}$ & $3.51( \pm 0.01)^{A b}$ & $3.41( \pm 0 ; 01)^{A c}$ & $3.76( \pm 0.57)^{A a}$ \\
\hline $\mathrm{Gel}+\mathrm{FCN}$ & $3.50( \pm 0.01)^{B b}$ & $3.58( \pm 0.01)^{A a}$ & $3.39( \pm 0.02)^{C a b}$ \\
\hline \multicolumn{4}{|l|}{ Moisture (\%) } \\
\hline Control & $94.69( \pm 0.42)^{A a}$ & $91.69( \pm 0.00)^{A a}$ & $88.22( \pm 4.76)^{A a}$ \\
\hline Glycerol & $94.34( \pm 0.42)^{A a}$ & $92.62( \pm 0.30)^{B a}$ & $91.66( \pm 0.15)^{C a}$ \\
\hline CS Gel & $93.94( \pm 0.09)^{A a}$ & $92.55( \pm 0.14)^{B a}$ & $92.12( \pm 0.08)^{B a}$ \\
\hline FCN & $94.58( \pm 0.21)^{A a}$ & $92.14( \pm 0.43)^{B a}$ & $90.54( \pm 0.23)^{C a}$ \\
\hline $\mathrm{Gel}+\mathrm{FCN}$ & $94.31( \pm 0.13)^{A a}$ & $92.00( \pm 0.47)^{B a}$ & $91.40( \pm 0.30)^{B a}$ \\
\hline \multicolumn{4}{|c|}{ Anthocyanin (g.L $\left.\mathrm{L}^{-1}\right)$} \\
\hline Control & $29.13( \pm 0.02)^{A c}$ & $25.97( \pm 0.01)^{C c}$ & $26.30( \pm 0.03)^{B a}$ \\
\hline Glycerol & $37.04( \pm 0.02)^{A a}$ & $27.71( \pm 0.08)^{B b}$ & $25.02( \pm 0.04)^{C b}$ \\
\hline CS Gel & $28.41( \pm 0.05)^{A d}$ & $23.98( \pm 0.06)^{B e}$ & $23.51( \pm 0.01)^{C c}$ \\
\hline $\mathrm{FCN}$ & $32.49( \pm 0.01)^{A b}$ & $25.66( \pm 0.08)^{B d}$ & $21.60( \pm 0.01)^{C d}$ \\
\hline $\mathrm{Gel}+\mathrm{FCN}$ & $26.00( \pm 0.04)^{B e}$ & $28.72( \pm 0.17)^{A a}$ & $21.14( \pm 0.05)^{C e}$ \\
\hline
\end{tabular}

Note: The storage time Day 0 represents the day of application of the edible coatings. Values represent the mean of three replicates with their standard error $( \pm \mathrm{SD}) .{ }^{A-C}$ For each trial, different superscript lowercase letters within a row denote significant differences $(\mathrm{p}<0.05)$ between the mean values according to Tukey's test. ${ }^{a-e}$ Different superscript capital letters in the same column denote significant differences $(\mathrm{p}<0.05)$ between the mean values according to Tukey's test 
$382 \mid$ Melo et al.

Table 3: Mean values of physicochemical quality parameters in strawberries stored at cold temperature for 12 days in the absence of edible coating (control) and with glycerol, chitosan gel (CS Gel), fungal chitosan nanoparticles (FCN) and chitosan gel enriched with fungal chitosan nanoparticles (Gel+FCN).

\begin{tabular}{|c|c|c|c|c|c|}
\hline \multirow{2}{*}{ Treatments } & \multicolumn{5}{|c|}{ Days of storage } \\
\hline & 0 & 3 & 6 & 9 & 12 \\
\hline \multicolumn{6}{|c|}{ Soluble solids (\%) } \\
\hline Control & $8.07( \pm 0.12)^{B b}$ & $8.13( \pm 0.06)^{B a}$ & $8.27( \pm 0.23)^{B a}$ & $8.53( \pm 0.46)^{B a}$ & $9.60( \pm 0.00)^{A a}$ \\
\hline Glycerol & $8.47( \pm 0.23)^{A a}$ & $8.03( \pm 0.06)^{A a b}$ & $8.13( \pm 0.23)^{A a}$ & $8.53( \pm 0.46)^{A a}$ & $8.67( \pm 0.23)^{A b}$ \\
\hline CS Gel & $8.00( \pm 0.00)^{A b}$ & $8.00( \pm 0.00)^{A b}$ & $8.00( \pm 0.00)^{A a}$ & $8.27( \pm 0.23)^{A a}$ & $8.40( \pm 0.04)^{A b}$ \\
\hline FCN & $8.07( \pm 0.12)^{B b}$ & $8.03( \pm 0.06)^{B a b}$ & $8.00( \pm 0.00)^{B a}$ & $8.00( \pm 0.00)^{B a}$ & $8.40( \pm 0.00)^{A b}$ \\
\hline $\mathrm{Gel}+\mathrm{FCN}$ & $8.00( \pm 0.00)^{A b}$ & $8.00( \pm 0.00)^{A b}$ & $8.00( \pm 0.00)^{A a}$ & $8.00( \pm 0.00)^{A a}$ & $8.27( \pm 0.23)^{A b}$ \\
\hline \multicolumn{6}{|c|}{ Titratable acidity (\% citric acid) } \\
\hline Control & $1.06( \pm 0.01)^{A a}$ & $1.04( \pm 0.02)^{A a}$ & $1.11( \pm 0.08)^{A a}$ & $1.06( \pm 0.11)^{A a}$ & $1.14( \pm 0.02)^{A a}$ \\
\hline Glycerol & $1.18( \pm 0.01)^{A a}$ & $0.89( \pm 0.42)^{B a}$ & $1.02( \pm 0.06)^{A B a b}$ & $0.94( \pm 0.01)^{B a}$ & $1.14( \pm 0.05)^{A a}$ \\
\hline CS Gel & $1.10( \pm 0.01)^{A a}$ & $1.00( \pm 0.01)^{A b a}$ & $0.92( \pm 0.01)^{B b}$ & $0.93( \pm 0.04)^{B a}$ & $1.08( \pm 0.02)^{A a b}$ \\
\hline FCN & $0.97( \pm 0.00)^{A a}$ & $0.78( \pm 0.23)^{A a}$ & $1.02( \pm 0.02)^{A a b}$ & $1.10( \pm 0.06)^{A a}$ & $1.08( \pm 0.01)^{A a b}$ \\
\hline $\mathrm{Gel}+\mathrm{FCN}$ & $1.02( \pm 0.15)^{A a}$ & $1.00( \pm 0.00)^{A a}$ & $1.03( \pm 0.00)^{A a b}$ & $1.05( \pm 0.03)^{A a}$ & $1.01( \pm 0.00)^{A b}$ \\
\hline \multicolumn{6}{|c|}{ Maturity index } \\
\hline Control & $7.58( \pm 0.05)^{A a}$ & $7.69( \pm 0.24)^{A a}$ & $7.39( \pm 0.31)^{A b}$ & $8.34( \pm 0.89)^{A a}$ & $8.38( \pm 0.16)^{A a}$ \\
\hline Glycerol & $7.14( \pm 0.20)^{B a}$ & $9.00( \pm 0.43)^{A a}$ & $8.00( \pm 0.22)^{A B a b}$ & $8.98( \pm 0.67)^{A a}$ & $7.76( \pm 0.34)^{A B a}$ \\
\hline CS Gel & $7.30( \pm 0.04)^{B a}$ & $8.02( \pm 0.57)^{A B a}$ & $8.74( \pm 0.07)^{A a}$ & $8.78( \pm 0.04)^{A a}$ & $7.55( \pm 0.11)^{B a}$ \\
\hline FCN & $8.24( \pm 0.00)^{A a}$ & $8.08( \pm 0.76)^{A a}$ & $7.80( \pm 0.16)^{A b}$ & $7.28( \pm 0.37)^{A a}$ & $7.74( \pm 0.05)^{A a}$ \\
\hline $\mathrm{Gel}+\mathrm{FCN}$ & $7.96( \pm 1.17)^{A a}$ & $8.00( \pm 0.00)^{A a}$ & $7.76( \pm 0.00)^{A b}$ & $7.62( \pm 0.20)^{A a}$ & $8.12( \pm 0.28)^{A a}$ \\
\hline \multicolumn{6}{|l|}{$\mathrm{pH}$} \\
\hline Control & $3.45( \pm 0.01)^{A b}$ & $3.47( \pm 0.01)^{A b}$ & $3.30( \pm 0.07)^{B c}$ & $3.32( \pm 0.00)^{B c}$ & $3.33( \pm 0.00)^{B d}$ \\
\hline Glycerol & $3.41( \pm 0.01)^{C c}$ & $3.50( \pm 0.01)^{A a}$ & $3.36( \pm 0.00)^{B b c}$ & $3.37( \pm 0.01)^{B c}$ & $3.37( \pm 0.01)^{B c d}$ \\
\hline CS Gel & $3.46( \pm 0.01)^{C b}$ & $3.50( \pm 0.00)^{B C a}$ & $3.52( \pm 0.01)^{B a}$ & $3.57( \pm 0.00)^{A a}$ & $3.54( \pm 0.00)^{A B a}$ \\
\hline FCN & $3.51( \pm 0.00)^{A a}$ & $3.41( \pm 0.00)^{B c}$ & $3.38( \pm 0.00)^{C D b c}$ & $3.37( \pm 0.00)^{D c}$ & $3.39( \pm 0.01)^{C c}$ \\
\hline $\mathrm{Gel}+\mathrm{FCN}$ & $3.44( \pm 0.01)^{A b}$ & $3.46( \pm 0.01)^{A b}$ & $3.43( \pm 0.02)^{A a b}$ & $3.45( \pm 0.04)^{A b}$ & $3.44( \pm 0.01)^{A b}$ \\
\hline \multicolumn{6}{|c|}{ Moisture (\%) } \\
\hline Control & $91.46( \pm 0.06)^{B a}$ & $91.27( \pm 0.47)^{B a}$ & $91.48( \pm 0.09)^{B b}$ & $91.88( \pm 0.13)^{B a}$ & $92.86( \pm 0.17)^{A b}$ \\
\hline Glycerol & $90.94( \pm 0.85)^{A a}$ & $92.38( \pm 0.48)^{A a}$ & $92.80( \pm 0.12)^{A a}$ & $91.65( \pm 0.74)^{A a}$ & $92.91( \pm 0.11)^{A b}$ \\
\hline CS Gel & $91.06( \pm 0.12)^{B a}$ & $91.48( \pm 0.11)^{B a}$ & $92.65( \pm 0.17)^{A a}$ & $92.49( \pm 0.21)^{A a}$ & $92.91( \pm 0.08)^{A b}$ \\
\hline FCN & $90.78( \pm 0.18)^{D a}$ & $91.31( \pm 0.08)^{C D a}$ & $92.13( \pm 0.28)^{A B a b}$ & $91.60( \pm 0.18)^{B C a}$ & $92.66( \pm 0.15)^{A b}$ \\
\hline $\mathrm{Gel}+\mathrm{FCN}$ & $92.08( \pm 0.01)^{C a}$ & $92.44( \pm 0.04)^{B C a}$ & $92.98( \pm 0.37)^{A B a}$ & $92.42( \pm 0.01)^{B C a}$ & $93.42( \pm 0.11)^{A a}$ \\
\hline \multicolumn{6}{|c|}{ Anthocyanin (g.L $\left.\mathrm{L}^{-1}\right)$} \\
\hline Control & $28.60( \pm 0.00)^{A c}$ & $28.23( \pm 0.03)^{A b}$ & $25.98( \pm 0.01)^{B a b}$ & $23.62( \pm 0.01)^{C c}$ & $22.71( \pm 0.31)^{D b}$ \\
\hline Glycerol & $39.88( \pm 0.03)^{A a}$ & $31.69( \pm 0.58)^{B a}$ & $24.87( \pm 1.17)^{C b}$ & $19.97( \pm 0.04)^{D e}$ & $21.05( \pm 0.06)^{D c}$ \\
\hline CS Gel & $30.01( \pm 0.16)^{A b}$ & $24.54( \pm 0.02)^{E d}$ & $26.43( \pm 0.02)^{D a}$ & $28.11( \pm 0.03)^{B a}$ & $27.64( \pm 0.00)^{C a}$ \\
\hline FCN & $27.53( \pm 0.00)^{A d}$ & $26.68( \pm 0.20)^{B c}$ & $22.52( \pm 0.00)^{C c}$ & $21.89( \pm 0.04)^{D d}$ & $22.50( \pm 0.02)^{C b}$ \\
\hline $\mathrm{Gel}+\mathrm{FCN}$ & $22.40( \pm 0.01)^{D e}$ & $25.31( \pm 0.24)^{B d}$ & $25.68( \pm 0.01)^{A a b}$ & $24.51( \pm 0.01)^{C b}$ & $22.51( \pm 0.01)^{D b}$ \\
\hline
\end{tabular}

Note: The storage time Day 0 represents the day of application of the edible coatings. Values represent the mean of three replicates with their standard error $( \pm \mathrm{SD}) .{ }^{A-E}$ For each trial, different superscript lowercase letters within a row denote significant differences $(\mathrm{p}<0.05)$ between the mean values according to Tukey's test. ${ }^{a-e}$ Different superscript capital letters in the same column denote significant differences $(\mathrm{p}<0.05)$ between the mean values according to Tukey's test. 

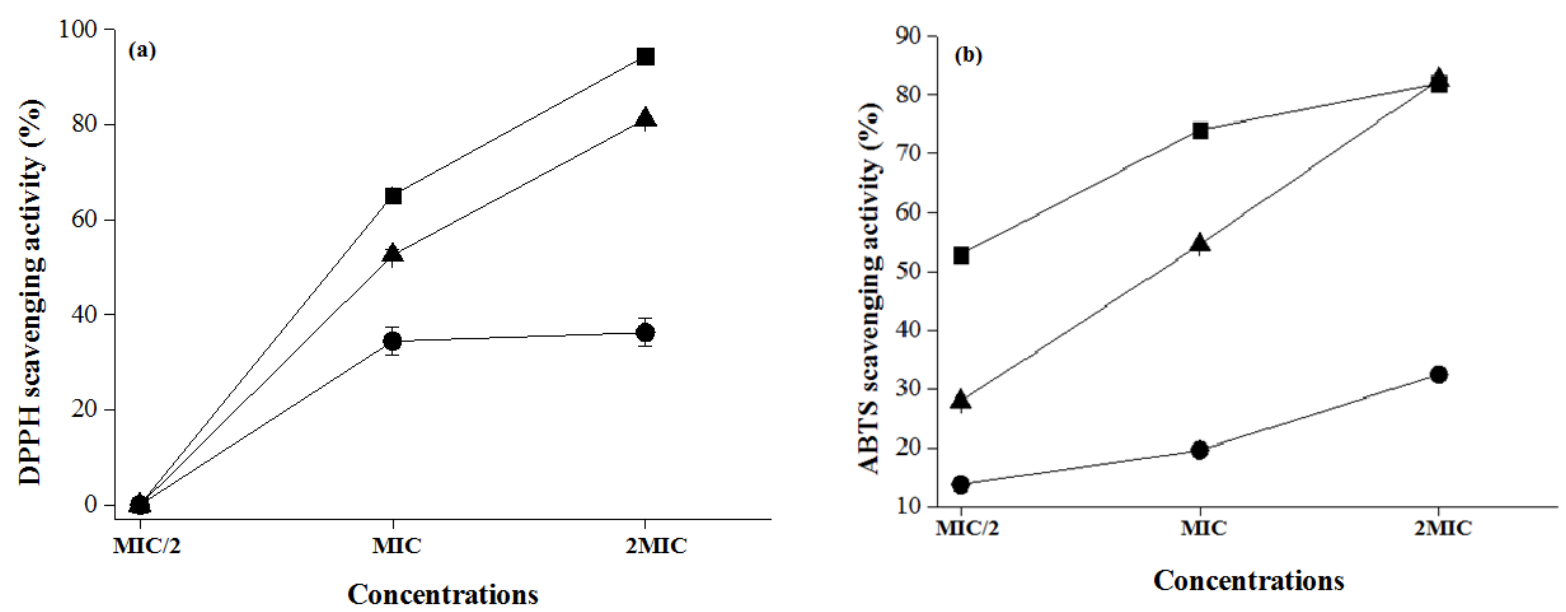

Figure 2: Scavenging effect of CS gel $(\mathbf{a})$, FCN $(\bullet)$ and CS gel + FCN ( $\mathbf{\Delta})$ towards DPPH (a) and ABTS (b) radicals.

and sugar, thereby increasing the soluble solids content (Cao, Guan, Dai, Li, \& Zhang, 2015). Coated strawberries presented lower values of soluble solids at the end of storage because chitosan modified the internal atmosphere of the fruit, reducing the $\mathrm{O}_{2}$ and increasing $\mathrm{CO}_{2}$. It could have reduced the respiration rate and the metabolic activity of the fruit, which also reduced the conversion of sugars into $\mathrm{CO}_{2}$ and water (Ghasemnezhad, Nezhad, \& Gerailoo, 2011). There was no significant difference $(\mathrm{p}>0.05)$ in the soluble solids content of the samples coated with edible chitosan-based coatings. Therefore, this result suggested that the capacity of chitosan to maintain the soluble solids content of strawberries was independent of the form of the polymer that was applied (gel or nanoparticles).

The titratable acidity values of the strawberries with and without edible coatings were maintained during the storage period at room temperature. According to Gol et al. (2013), the titratable acidity is directly related to the amount of organic acids present in the fruit and in the strawberry the main acids are citric and malic. A reduction in the fruit acidity could occur due to changes in fruit metabolism or the use of organic acids in the respiratory process (Hajji, Younes,
Affes, Boufi, \& Nasri, 2018). The edible coatings reduce the fruit respiration rate that delays the use of organic acids which maintains titratable acid values during storage (Yaman \& Bayoindirli, 2002).

The strawberries stored at the cold temperature also maintained titratable acidity values in relation to day 0 . However, on day 12, the strawberries coated with the gel+FCN differed significantly $(\mathrm{p}<0.05)$ from the control sample and presented the lowest titratable acidity value. This could be related to the low values of titratable acidity that this strawberry sample already had from the beginning of the analysis. In this case, the edible coating only maintained these values, which showed that the gel $+\mathrm{FCN}$ was able to retard the metabolism of the fruit, and consequently decreased the consumption of the organic acids, so maintaining the titratable acidity.

The strawberries with the edible coatings and stored at room temperature decreased their maturation index from the third day of storage. In addition, at the same temperature, the coated samples differed significantly $(\mathrm{p}<0.05)$ at the end of the storage period when compared to the control sample.

The increase in maturity index during storage is 
associated with the progression of the fruit ripening process (Perdones, Sanchez-Gonzalez, Chiralt, \& Vargas, 2012). The low values of the maturity index in the coated samples showed the capacity of the edible chitosan based coatings to delay the metabolic activity of the strawberries. However, in cold storage, at in the end of the storage period, the maturity index of the strawberries with and without coatings did not differ significantly $(\mathrm{p}>0.05)$. According to Valenzuela et al. (2015), this increase in the maturity index during the final storage period is a result of the fruit senescence process.

Strawberries coated with FCN and gel + FCN kept the maturity index constant, which reflected the delay of fruit senescence. Otherwise, strawberries coated with glycerol and CS gel showed an increase in their maturation index.

The anthocyanin content can also reflect the delay of fruit senescence. At the end of storage, all samples showed a decrease $(\mathrm{p}<0.05)$ in the anthocyanin content. However, on the last day of storage, at room temperature the control sample had the highest anthocyanin content $(\mathrm{p}<$ 0.05). The edible coatings formed a barrier between the fruit and the environment, which modified the concentrations of $\mathrm{CO}_{2}$ and $\mathrm{O}_{2}$ in the fruit affecting the synthesis and degradation of anthocyanin. The greatest accumulation of anthocyanin in the control sample may have been related to its advanced maturation, which includes the synthesis of this pigment from glucose (Meng, Li, Liu, \& Tian, 2008).

However, anthocyanin, the pigment responsible for the red colour of strawberries, affects the sensory quality and health benefits of this fruit (Velde, Tarola, Güemes, \& Pirovani, 2013). Therefore, low values of this pigment can affect the sensorial acceptability of the fruit. At cold temperatures, the strawberries coated with gel+FCN maintained their anthocyanin content (first and last day of storage) and indirectly the sensorial quality of the fruit.

Furthermore, there was a decrease in the $\mathrm{pH}$ of the samples. According to Famiani, Battistelli, Moscatello, Cruz-Castillo, and Walker (2015), in the pulp of many fruits during maturation there is an increase of organic acids. It has been shown that the main organic acid accumulated in ripe strawberries is citric acid (Famiani et al., 2005), which may be involved in the decrease of the $\mathrm{pH}$ observed in the samples analyzed.

The strawberries coated with FCN and gel+FCN and stored at room temperature and at cold temperatures, respectively, were the only ones that did not present a significant difference $(\mathrm{p}>0.05)$ in the $\mathrm{pH}$ values during all the evaluated days, suggesting a delay in the senescence of these samples. It is important to note that only the coatings that had chitosan nanoparticles in their composition (alone or mixed with the gel) were able to maintain $\mathrm{pH}$ values and delay the senescence of fruits. Therefore, when chitosan is in nanoparticle form, it is possible that it potentiates its protective effects contributing to the conservation of the physical-chemical parameters of the fruits (Castelo Branco Melo et al., 2018).

The percentage of moisture in the strawberries showed that, at the end of the storage period at room temperature, the moisture content of the samples did not differ significantly ( $p>0.05)$. The same behaviour was found in the fruit stored at the cold temperature. The only exception was the strawberries coated with gel+FCN, which presented the highest moisture content on the $12^{\text {th }}$ day that differed significantly $(\mathrm{p}<0.05)$ from all other samples. Therefore, the storage temperature did not influence in the moisture percentage of the strawberries. Castelo Branco Melo et al. (2018) suggests that the longer storage time of the fruits at refrigeration temperature (12 days) in relation to fruits stored at room temperature (6 days) may also favour an advance in fruit metabolism which contributes to a higher loss of moisture.

The gel + FCN coating applied to strawberries stored in refrigeration showed that the association of these two forms of chitosan could significantly improve the barrier properties of an edible coating. According to Amarante, Banks, and Ganesh (2001), gas exchanges between the fruit and the environment occur through open pores and the high permeability of the skin fruit. The chitosan coatings act as a barrier between the fruit and the environment, thus avoiding the loss of moisture (Guerreiro, Gago, Faleiro, Miguel, $\&$ Antunes, 2015). When we added nanoparticles to this type of coating, we created a double blocking effect - the barrier formed by the CS gel and FCN blocked the pores present in the straw- 
Strawberries coated with fungal chitosan (gel, nanoparticles, gel + nanoparticles) 385

berries (Castelo Branco Melo et al., 2018).

In addition, it is important to note that the concentration of the gel and the nanoparticles (2 g. $L^{-1}+1$ g. $\left.L^{-1}\right)$ in the coating made by the mixture was much lower than the concentration used in the coating made only with the CS gel $\left(5\right.$ g. $\left.\mathrm{L}^{-1}\right)$ and only with FCN $\left(2.5\right.$ g. $\left.\mathrm{L}^{-1}\right)$. It showed that the two forms of chitosan presented a potentiation of their barrier properties when together, even in low concentrations.

\subsection{Weight loss}

The samples stored at room temperature had high weight loss and there was no statistically significant difference $(\mathrm{p}>0.05)$ between the results of these samples (Fig. 3a). According to Garcia, Medina, and Olias (1998), the maximum commercially acceptable limit for strawberries weight loss is $6 \%$. In our research, all samples stored at room temperature exhibited weight loss percentages higher than the acceptable limit. Any edible coating was able to prevent significant weight loss at room temperature. This could have occurred due to the storage temperature, since the cold temperature decreased the weight loss of the strawberries by about 15 times when compared to the room temperature. Ventura-Aguilar, Bautista-Banos, Flores-Garcia, and Zavaleta-Avejar (2018) also found a similar decrease when they applied chitosan coatings and cinnamon extract on strawberries stored at cold temperatures.

Fruit weight loss is associated with the fruit respiration and evaporation processes. Therefore, at high temperatures, there is an increase in the respiratory rate of the fruit, associated with a loss of moisture and weight (Ali, Noh, \& Mustafa, 2015). So, the weight loss was more intense in samples stored at room temperature than at the cold temperature. A similar result was found by Castelo Branco Melo et al. (2018), who used CS gel enriched with FCN edible coatings to preserve table grapes.

According to Khalifa, Barakat, El-Mansy, and Soliman (2016), chitosan is able to decrease weight loss in fruit due to its filmogenic property. This polymer acts as a barrier to water vapour and the gaseous exchanges between the fruit and the external environment. At cold temperatures, the strawberries coated with CS gel did not present a statistically significant difference $(\mathrm{p}$ $>0.05)$ when compared to the fruit coated with FCN or CS gel enriched with FCN. Kaewklin, Siripatrawan, Suwanagul, and Lee (2018), analyzed the weight loss of tomatoes coated with CS film and chitosan-titanium dioxide nanocomposite film and also reported that there was no statistically significant difference $(p>0.05)$ in the weight loss between the tomatoes coated with the CS nanocomposite and CS alone.

Therefore, the prevention of weight loss is more related to the formation of the external barrier produced by the edible coating than the form of the polymer present in this coating. However, all strawberries with the edible coatings produced in the present research and stored at cold temperatures had a commercially acceptable weight loss according to the limit defined by Garcia et al. (1998).

\subsection{Decay rate}

The lowest percentage of decay was found in strawberries coated with FCN alone or FCN associated with CS gel (Fig. 3b). These strawberry samples differed statistically $(\mathrm{p}<0.05)$ from the control samples at both temperatures. Otherwise, the fruit coated with CS gel did not statistically differ $(p>0.05)$ from the control fruit at any temperature analyzed. This suggested that there was an improvement in the conservative action of chitosan when this polymer is in the nanoparticle form.

According to Hajji et al. (2018), chitosan plays a dual function by interfering directly in the fungal growth through the hydrolysis of chitin (important cellular component of the fungus) and activating many biological processes in plant tissues. Furthermore, the antimicrobial activity of this polymer is related to its ability to induce severe cellular damage to the molds and to interfere in the polygalacturonases secretion of fruit (Velickova, Winkelhausen, Kuzmanova, Alves, \& Moldao-Martins, 2013).

The edible coating itself is another factor that contributes to a lower percentage of visible infection in fruits, since it acts as a barrier that pre-

\begin{tabular}{l|l|l|l} 
IJFS | October 2020 | Volume 9 & pages 373-393
\end{tabular} 
386 | Melo et al.
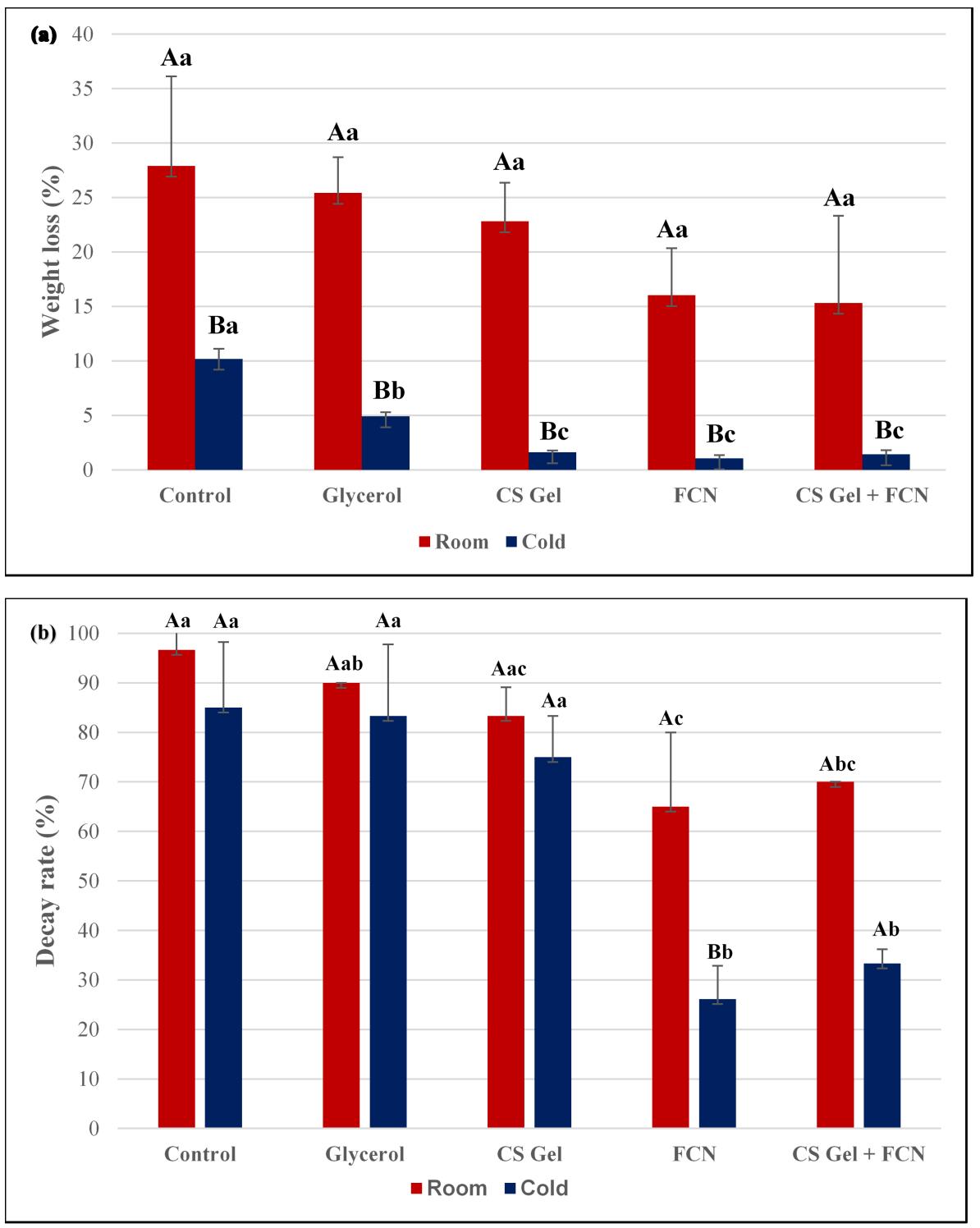

Figure 3: The weight loss (a) and the decay rate (b) of strawberries after 6 and 12 days of room and cold stored temperatures, respectively.

Note: Values represent the mean of three replicates with their standard error $( \pm \mathrm{SD}) .{ }^{a-c}$ Different superscript lowercase letters at the same temperature denote significant differences $(\mathrm{p}<0.05)$ between the mean values according to Tukey's test. ${ }^{A-B}$ Different superscript capital letters between the temperatures denote significant differences $(\mathrm{p}<0.05)$ between the mean values according to Tukey's test. 


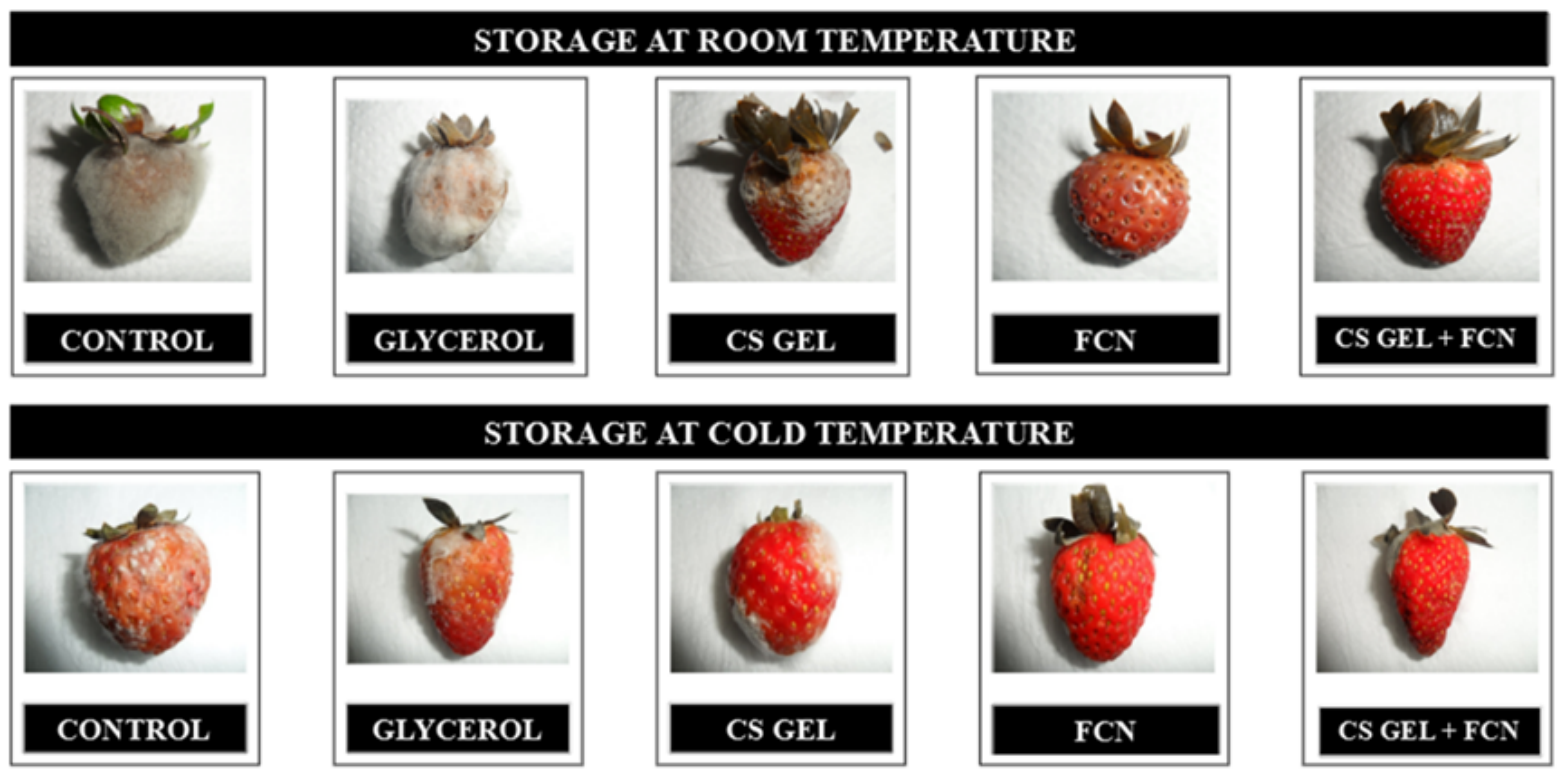

Figure 4: The appearance of uncoated and coated strawberries after 6 and 12 days of room and cold stored temperatures, respectively

vents the contact of the strawberry with external microorganisms (Hajji et al., 2018). The edible coatings also act by retarding the senescence of fruits and the resistance to fungal infections can be improved by the delay in senescence (Gol et al., 2013).

A significant decrease $(\mathrm{p}<0.05)$ in the decay rate was observed when FCN coating was applied to the strawberries stored at cold temperatures in relation to strawberries with this same type of coating, but stored at room temperatures (Fig. 4). Similar to the results found in the present research, Castelo Branco Melo et al. (2018) also observed that at cold temperatures the conservative action of the chitosan nanoparticles edible coating is improved. Low temperature storage slows the physiological processes in fruit and pathogens have weaker pathogenicity, and this reduces the incidence of decay compared to fruit stored at room temperature, which decay rapidly (Meng et al., 2008). Therefore, the present research confirms the idea that the use of chitosan with nanoparticles enhances its conservative action on fruits, especially on strawberries. This action could be more effective when the fruit is stored at low temperatures.

\subsection{Sensory evaluation}

Changes in sensory attributes are presented in Table 4. Uncoated fruit received the highest scores for all analyzed attributes when compared to coated fruit. However, there were no significant differences $(\mathrm{p}>0.05)$ between the control, CS gel and FCN samples in relation to the strawberry colour, taste, flavour, firmness and overall evaluation. It could be suggested that the form of the chitosan polymer (gel or nanoparticles) did not influence in the sensory quality of the strawberries. According to Vargas, Albors, Chiralt, and Gonzalez-Martinez (2006), chitosan could show an astringent taste due to its dissolution in an acidic medium, but this was not observed in the strawberries coated with CS gel and FCN, since the sensory analysis was performed on the third day of storage. This result is in agreement with the results reported by Velickova et al. (2013) and Castelo Branco Melo et al. (2018).

It is important to note that the edible coating 
Table 4: Mean sensory scores for uncoated (control) fruit and fruit coated with glycerol, chitosan gel (CS gel), fungal chitosan nanoparticles (FCN), and gel enriched with fungal chitosan nanoparticles (Gel + FCN) stored at cold temperature.

\begin{tabular}{lccccc}
\hline Attributes & Control & Glycerol & CS Gel & FCN & Gel + FCN \\
\hline Appearance & $7.81( \pm 1.51)^{a}$ & $6.61( \pm 1.79)^{c}$ & $6.94( \pm 1.91)^{b c}$ & $7.52( \pm 1.44)^{a b}$ & $6.94( \pm 1.75)^{b c}$ \\
Colour & $7.87( \pm 1.46)^{a}$ & $6.95( \pm 1.66)^{c}$ & $7.30( \pm 1.71)^{a b c}$ & $7.64( \pm 1.44)^{a b}$ & $7.07( \pm 1.75)^{b c}$ \\
Flavour & $7.50( \pm 1.55)^{a}$ & $6.95( \pm 1.70)^{a b}$ & $7.22( \pm 1.55)^{a b}$ & $7.20( \pm 1.56)^{a b}$ & $6.78( \pm 1.66)^{b}$ \\
Firmness & $8.04( \pm 1.04)^{a}$ & $7.64( \pm 1.43)^{a}$ & $7.52( \pm 1.41)^{a}$ & $7.70( \pm 1.49)^{a}$ & $7.59( \pm 1.37)^{a}$ \\
Taste & $7.61( \pm 1.80)^{a}$ & $6.86( \pm 1.75)^{b}$ & $7.51( \pm 1.53)^{a b}$ & $7.58( \pm 1.70)^{a}$ & $6.85( \pm 1.94)^{b}$ \\
Overall evaluation & $7.77( \pm 1.46)^{a}$ & $7.02( \pm 1.48)^{b}$ & $7.43( \pm 1.42)^{a b}$ & $7.68( \pm 1.47)^{a}$ & $6.85( \pm 1.71)^{b}$ \\
\hline
\end{tabular}

Note: Sensory attributes were evaluated by one hundred untrained tasters after 3 days from the application of the edible coatings. The strawberries were stored at cold temperature before sensory evaluation. Values represent the mean with their standard error $( \pm \mathrm{SD}) \cdot{ }^{a-c}$ For each trial, different superscript lowercase letters within a row denote significant differences $(\mathrm{p}<0.05)$ between the mean values according to Tukey's test.

made by the mixture of CS gel and FCN differed significantly $(\mathrm{p}<0.05)$ from the control group for all attributes, except for the firmness. As previously described in the present research, the gel+FCN coating applied to strawberries stored in refrigeration showed that the association of these two forms of chitosan (gel and nanoparticles) could significantly improve the barrier properties of an edible coating. The strawberries coated with gel+FCN kept the maturity index and $\mathrm{pH}$ constant and presented the highest humidity percentage. The application of this type of coating could have delayed the ripening process, which contributed to the lower acceptance of this sample.

When asked to report about the intent to purchase, the panellists reported differences between uncoated and coated fruit. The control strawberries did not present significant differences $(\mathrm{p}>$ $0.05)$ in relation to fruit coated with FCN. These samples exhibited scores around four (control: $4.34 \pm 1.03$ and FCN: $4.09 \pm 1.10)$ and were the most accepted, followed by CS gel $(3.84 \pm 1.10)$, which did not differ $(\mathrm{p}>0.05)$ from FCN.

No difference $(p>0.05)$ in preference was observed between fruit coated with glycerol (3.61 \pm $1.10)$ and gel + FCN $(3.64 \pm 1.14)$. These groups were the least appreciated sample, which is in agreement with the acceptability test. However all samples exhibited scores around four which shows that the tasters would "possibly buy" the fruit. The same scores were found by our previous study when we applied an edible coating made by CS gel and FCN to grapes (Castelo Branco Melo et al., 2018). These scores made the use of the edible coatings produced in the present study feasable on a commercial level based on the analysis of the sensory aspects.

\section{Conclusions}

All chitosan based edible coatings were effective in maintaining the physicochemical, sensory and microbiological qualities of the postharvest strawberries. However, the coating made with FCN+CS gel was the most effective in maintaining these quality parameters of the strawberries and presented the best antifungal activity against the phytopathogenic fungi tested. The sensory evaluation of the strawberries showed that fruit coated with FCN received similar scores to control group, which suggest that the FCN did not modify the sensory quality of the fruit.

Based on these results, edible coatings made with different forms of chitosan, especially the mixture of FCN and CS gel, could be used to improve the post-harvest quality of strawberries. In addition, the application of nanotechnology could be a good alternative to improve the properties 
Strawberries coated with fungal chitosan (gel, nanoparticles, gel + nanoparticles) | 389

of chitosan, as well as increase the cost benefit of the use of edible coatings based on this polymer.

\section{Acknowledgements}

The authors thank the Kitozyme-Company for providing the chitosan, the Coordenação de Aperfeiçoamento de Pessoal de Nível Superior, process $\mathrm{n}^{o}$ CAPES/PROEX 1734/2015, the Fundação de Apoio a Ciência e Tecnologia do Estado de Pernambuco, process $n^{\circ}$ APQ 0566-5.07/14, Universidade Federal de Pernambuco process PROPESQ $n^{\circ} 04 / 2018$, for financial support and a research grant, the Núcleo de Pesquisa em Ciências Ambientais da Universidade Católica de Pernambuco and the Centro de Tecnologias Estratégicas do Nordeste for the availability of infrastructure.

\section{References}

Ali, A., Noh, N. M., \& Mustafa, M. A. (2015). Antimicrobial activity of chitosan enriched with lemongrass oil against anthracnose of bell pepper. Food Packaging And Shelf Life, 3, 56-61. doi:10.1016/j.fpsl.2014.10. 003

Allan, C. R., Allan, C. R., \& Hadwiger, L. E. (1979). The fungicidal effect of chitosan on fungi of varying cell wall composition.

Amarante, C., Banks, N. H., \& Ganesh, S. (2001). Relationship between character of skin cover of coated pears and permeance to water vapour and gases. Postharvest Biology and Technology, 21(3), 291-301. doi:10.1016/S0925-5214(00)00176-9

AOAC. (2012). Association of Official Analytical Chemists International. Official methods of analysis of AOAC international (19th ed.). Method 934.06, method 981.12, method 920.149, method 932.12.

Badawy, M. E., \& Rabea, E. I. (2011). A biopolymer chitosan and its derivatives as promising antimicrobial agents against plant pathogens and their applications in crop protection. International Journal of Carbohydrate Chemistry, 2011.
Berger, L. R. R., Stamford, T. C. M., de Oliveira, K. Á. R., Pessoa, A. d. M. P., de Lima, M. A. B., Pintado, M. M. E., ... de Souza, E. L. (2018). Chitosan produced from mucorales fungi using agroindustrial by-products and its efficacy to inhibit colletotrichum species. International Journal of Biological Macromolecules, 108, 635641.

Bugnicourt, L., Alcouffe, P., \& Ladavière, C. (2014). Elaboration of chitosan nanoparticles: Favorable impact of a mild thermal treatment to obtain finely divided, spherical, and colloidally stable objects. Colloids and Surfaces A: Physicochemical and Engineering Aspects, 457, 476-486.

Calvo, P., RemunanLopez, C., VilaJato, J. L., \& Alonso, M. J. (1997). Novel hydrophilic chitosan-polyethylene oxide nanoparticles as protein carriers. Journal of Applied Polymer Science, 63(1), 125-132. doi:10. 1002 / (SICI ) 1097 - 4628(19970103 ) 63 : 1〈125::AID-APP13〉3.0.CO;2-4

Cao, F., Guan, C., Dai, H., Li, X., \& Zhang, Z. (2015). Soluble solids content is positively correlated with phosphorus content in ripening strawberry fruits. Scientia Horticulturae, 195, 183-187. doi:10.1016/j . scienta.2015.09.018

Castelo Branco Melo, N. F., de MendoncaSoares, B. L., Diniz, K. M., Leal, C. F., Canto, D., Flores, M. A. P., ... Montenegro Stamford, T. C. (2018). Effects of fungal chitosan nanoparticles as eco-friendly edible coatings on the quality of postharvest table grapes. Postharvest Biology And Technology, 139, 56-66. doi:10.1016/j.postharvbio. 2018.01 .014

Chen, W., Li, Y., Yang, S., Yue, L., Jiang, Q., \& Xia, W. (2015). Synthesis and antioxidant properties of chitosan and carboxymethyl chitosan-stabilized selenium nanoparticles. Carbohydrate Polymers, 132, 574-581. doi:10.1016/j.carbpol.2015.06.064

Dantas Guerra, I. C., Lima de Oliveira, P. D., de Souza Pontes, A. L., Suassuna Carneiro Lucio, A. S., Tavares, J. F., BarbosaFilho, J. M., ... de Souza, E. L. (2015). Coatings comprising chitosan and mentha piperita l. or mentha $\mathrm{x}$ villosa huds es-

\begin{tabular}{l|l|l|l} 
IJFS | October 2020 | Volume 9 & pages 373-393
\end{tabular} 
sential oils to prevent common postharvest mold infections and maintain the quality of cherry tomato fruit. International Journal Of Food Microbiology, 214, 168-178. doi:10. 1016/j.ijfoodmicro.2015.08.009

Dhital, R., Joshi, P., Becerra-Mora, N., Umagiliyage, A., Chai, T., Kohli, P., \& Choudhary, R. (2017). Integrity of edible nanocoatings and its effects on quality of strawberries subjected to simulated in-transit vibrations. LWT - Food Science and Technology, 80, 257-264.

dos Santos, N. S. T., Aguiar, A. J. A. A., de Oliveira, C. E. V., de Sales, C. V., e Silva, S. d. M., da Silva, R. S., ... de Souza, E. L. (2012). Efficacy of the application of a coating composed of chitosan and Origanum vulgare l. essential oil to control Rhizopus stolonifer and Aspergillus niger in grapes (Vitis labrusca l.) Food Microbiology, 32(2), 345-353.

Eshghi, S., Hashemi, M., Mohammadi, A., Badii, F., Mohammadhoseini, Z., \& Ahmadi, K. (2014). Effect of nanochitosan-based coating with and without copper loaded on physicochemical and bioactive components of fresh strawberry fruit (Fragaria $x$ ananassa duchesne) during storage. Food and Bioprocess Technology, 7(8), 23972409. doi:10.1007/s11947-014-1281-2

Famiani, F., Battistelli, A., Moscatello, S., CruzCastillo, J. G., \& Walker, R. P. (2015). The organic acids that are accumulated in the flesh of fruits: Occurrence, metabolism and factors affecting their contents-a review. Revista Chapingo Serie Horticultura, $21(2), 97-128$.

Famiani, F., Cultrera, N. G. M., Battistelli, A., Casulli, V., Proietti, P., Standardi, A., ... Walker, R. P. (2005). Phosphoenolpyruvate carboxykinase and its potential role in the catabolism of organic acids in the flesh of soft fruit during ripening. Journal of Experimental Botany, 56(421), 2959-2969.

Fan, W., Yan, W., Xu, Z., \& Ni, H. (2012). Formation mechanism of monodisperse, low molecular weight chitosan nanoparticles by ionic gelation technique. Colloids and Surfaces B-biointerfaces, 90, 21-27. doi:10 . 1016/j.colsurfb.2011.09.042
Garcia-Rincon, J., Vega-Perez, J., GuerraSanchez, M. G., Hernandez-Lauzardo, A. N., Pena-Diaz, A., \& Velazquez-Del Valle, M. G. (2010). Effect of chitosan on growth and plasma membrane properties of rhizopus stolonifer (ehrenb.:fr.) vuill. Pesticide Biochemistry and Physiology, 97(3), 275-278. doi:10.1016/j.pestbp.2010.03.008

Garcia, J. M., Medina, R. J., \& Olias, J. M. (1998). Quality of strawberries automatically packed in different plastic films. Journal of Food Science, 63(6), 1037-1041.

Ghasemnezhad, M., Nezhad, M. A., \& Gerailoo, S. (2011). Changes in postharvest quality of loquat (Eriobotrya japonica) fruits influenced by chitosan. Horticulture Environment and Biotechnology, 52(1), 40-45. doi:10.1007/s13580-011-0028-5

Gol, N. B., Patel, P. R., \& Rao, T. V. R. (2013). Improvement of quality and shelflife of strawberries with edible coatings enriched with chitosan. Postharvest Biology And Technology, 85, 185-195. doi:10.1016/ j.postharvbio.2013.06.008

Guerreiro, A. C., Gago, C. M. L., Faleiro, M. L., Miguel, M. G. C., \& Antunes, M. D. C. (2015). The use of polysaccharide-based edible coatings enriched with essential oils to improve shelf-life of strawberries. Postharvest Biology and Technology, 110, 51-60. doi:10.1016/j.postharvbio.2015.06.019

Hajji, S., Younes, I., Affes, S., Boufi, S., \& Nasri, M. (2018). Optimization of the formulation of chitosan edible coatings supplemented with carotenoproteins and their use for extending strawberries postharvest life. Food Hydrocolloids, 83, 375-392.

Kaewklin, P., Siripatrawan, U., Suwanagul, A., \& Lee, Y. S. (2018). Active packaging from chitosan-titanium dioxide nanocomposite film for prolonging storage life of tomato fruit. International Journal of Biological Macromolecules, 112, 523-529. doi:10. 1016/j.ijbiomac.2018.01.124

Khalifa, I., Barakat, H., El-Mansy, H. A., \& Soliman, S. A. (2016). Enhancing the keeping quality of fresh strawberry using chitosanincorporated olive processing wastes. Food Bioscience, 13, 69-75. 
Strawberries coated with fungal chitosan (gel, nanoparticles, gel + nanoparticles) 391

Kheiri, A., Jorf, S. A. M., Malihipour, A., Saremi, H., \& Nikkhah, M. (2016). Application of chitosan and chitosan nanoparticles for the control of fusarium head blight of wheat (Fusarium graminearum) in vitro and greenhouse. International Journal of Biological Macromolecules, 93(A), 12611272. doi:10.1016/j.ijbiomac.2016.09.072

Kiilll, C. P., Barud, H. d. S., Santagneli, S. H., Lima Ribeiro, S. J., Silva, A. M., Tercjak, A., ... Daflon Gremiao, M. P. (2017). Synthesis and factorial design applied to a novel chitosan/sodium polyphosphate nanoparticles via ionotropic gelation as an RGD delivery system. Carbohydrate Polymers, 15\%, 1695-1702. doi:10.1016/ j . carbpol.2016.11.053

Kong, M., Chen, X. G., Xing, K., \& Park, H. J. (2010). Antimicrobial properties of chitosan and mode of action: A state of the art review. International journal of food microbiology, 144(1), 51-63.

Larrauri, J. A., Ruperez, P., \& SauraCalixto, F. (1997). Effect of drying temperature on the stability of polyphenols and antioxidant activity of red grape pomace peels. Journal of Agricultural and Food Chemistry, 45(4), 1390-1393. doi:10.1021/jf960282f

Lee, S. M., Song, K. C., \& Lee, B. S. (2010). Antibacterial activity of silver nanoparticles prepared by a chemical reduction method. Korean Journal of Chemical Engineering, 27(2), 688-692.

Lees, D. H., \& Francis, F. J. (1972). Standardization of pigment analyses in cranberries. HortScience.

Ma, Z., Garrido-Maestu, A., \& Jeong, K. C. (2017). Application, mode of action, and in vivo activity of chitosan and its micro-and nanoparticles as antimicrobial agents: A review. Carbohydrate polymers, 176, 257265.

Meng, X., Li, B., Liu, J., \& Tian, S. (2008). Physiological responses and quality attributes of table grape fruit to chitosan preharvest spray and postharvest coating during storage. Food Chemistry, 106(2), 501-508.

MubarakAli, D., LewisOscar, F., Gopinath, V., Alharbi, N. S., Alharbi, S. A., \& Thajuddin, N. (2018). An inhibitory ac- tion of chitosan nanoparticles against pathogenic bacteria and fungi and their potential applications as biocompatible antioxidants. Microbial Pathogenesis, 114, 323-327. doi:10.1016/j.micpath.2017.11. 043

Muzzarelli, R. A. A., Boudrant, J., Meyer, D., Manno, N., DeMarchis, M., \& Paoletti, M. G. (2012). Current views on fungal chitin/chitosan, human chitinases, food preservation, glucans, pectins and inulin: A tribute to henri braconnot, precursor of the carbohydrate polymers science, on the chitin bicentennial. Carbohydrate Polymers, 87(2), 995-1012. doi:10 . 1016/j. carbpol.2011.09.063

Oregel-Zamudio, E., Angoa-Pérez, M. V., Oyoque-Salcedo, G., Aguilar-González, C. N., \& Mena-Violante, H. G. (2017). Effect of candelilla wax edible coatings combined with biocontrol bacteria on strawberry quality during the shelf-life. Scientia Horticulturae, 214, 273-279.

Paomephan, P., Assavanig, A., Chaturongakul, S., Cady, N. C., Bergkvist, M., \& Niamsiri, N. (2018). Insight into the antibacterial property of chitosan nanoparticles against Escherichia coli and Salmonella typhimurium and their application as vegetable wash disinfectant. Food Control, 86 , 294-301.

Park, Y., Kim, M.-H., Park, S.-C., Cheong, H., Jang, M.-K., Nah, J.-W., Hahm, K.-S., et al. (2008). Investigation of the antifungal activity and mechanism of action of lmws-chitosan. Journal Microbiol Biotechnol, 18(10), 1729-1734.

Perdones, A., Sanchez-Gonzalez, L., Chiralt, A., \& Vargas, M. (2012). Effect of chitosanlemon essential oil coatings on storagekeeping quality of strawberry. Postharvest Biology and Technology, 70, 32-41. doi:10. 1016/j.postharvbio.2012.04.002

Pilon, L., Spricigo, P. C., Miranda, M., de Moura, M. R., Assis, O. B. G., Mattoso, L. H. C., \& Ferreira, M. D. (2015). Chitosan nanoparticle coatings reduce microbial growth on fresh-cut apples while not affecting quality attributes. International Journal of Food Science \& Technology, 50(2), 440-448. 
Saharan, V., Sharma, G., Yadav, M., Choudhary, M. K., Sharma, S. S., Pal, A., .. . Biswas, P. (2015). Synthesis and in vitro antifungal efficacy of $\mathrm{Cu}$-chitosan nanoparticles against pathogenic fungi of tomato. International Journal of Biological Macromolecules, 75, 346-353. doi:10.1016/j.ijbiomac.2015.01. 027

Severino, P., Andreani, T., Macedo, A. S., Fangueiro, J. F., Santana, M. H. A., Silva, A. M., \& Souto, E. B. (2012). Current state-of-art and new trends on lipid nanoparticles (sln and nlc) for oral drug delivery. Journal of Drug Delivery, 2012.

Shahbazi, Y. (2018). Application of carboxymethyl cellulose and chitosan coatings containing Mentha spicata essential oil in fresh strawberries. International journal of biological macromolecules, 112, 264-272.

Sharma, N., \& Tripathi, A. (2008). Effects of Citrus sinensis (L.) Osbeck epicarp essential oil on growth and morphogenesis of $A s$ pergillus niger (L.) Van Tieghem. Microbiological Research, 163(3), 337-344. doi:10. 1016/j.micres.2006.06.009

Siripatrawan, U., \& Harte, B. R. (2010). Physical properties and antioxidant activity of an active film from chitosan incorporated with green tea extract. Food Hydrocolloids, 24 (8), 770-775. doi:10.1016/j . foodhyd. 2010.04.003

Sullivan, D. J., Cruz-Romero, M., Collins, T., Cummins, E., Kerry, J. P., \& Morris, M. A. (2018). Synthesis of monodisperse chitosan nanoparticles. Food Hydrocolloids, 83, 355364. doi:10.1016/j.foodhyd.2018.05.010

Tsai, M.-L., Chen, R.-H., Bai, S.-W., \& Chen, W.-Y. (2011). The storage stability of chitosan/tripolyphosphate nanoparticles in a phosphate buffer. Carbohydrate Polymers, 84 (2, SI), 756-761. 11th International Conference on Chitin and Chitosan (11th ICCC), Taipei, TAIWAN, SEP 0609, 2009. doi:10.1016/j.carbpol.2010.04.040

Valenzuela, C., Tapia, C., López, L., Bunger, A., Escalona, V., \& Abugoch, L. (2015). Effect of edible quinoa protein-chitosan based films on refrigerated strawberry (Fragaria $x$ ananassa) quality. Electronic Journal of Biotechnology, 18(6), 406-411.
Vargas, M., Albors, A., Chiralt, A., \& GonzalezMartinez, C. (2006). Quality of cold-stored strawberries as affected by chitosan-oleic acid edible coatings. Postharvest Biology and Technology, 41(2), 164-171. doi:10 . 1016/j.postharvbio.2006.03.016

Vasconcelos de Oliveira, C. E., Magnani, M., de Sales, C. V., de Souza Pontes, A. L., Campos-Takaki, G. M., Montenegro Stamford, T. C., \& de Souza, E. L. (2014a). Effects of chitosan from cunninghamella elegans on virulence of postharvest pathogenic fungi in table grapes (Vitis labrusca L.) International Journal of Food Microbiology, 171, 54-61. doi:10. 1016/j.ijfoodmicro.2013.11.006

Vasconcelos de Oliveira, C. E., Magnani, M., de Sales, C. V., de Souza Pontes, A. L., Campos-Takaki, G. M., Montenegro Stamford, T. C., \& de Souza, E. L. (2014b). Effects of post-harvest treatment using chitosan from mucor circinelloides on fungal pathogenicity and quality of table grapes during storage. Food Microbiology, 44, 211219.

Velde, F. V., Tarola, A. M., Güemes, D., \& Pirovani, M. E. (2013). Bioactive compounds and antioxidant capacity of camarosa and selva strawberries (Fragaria $x$ ananassa Duchesne). Foods, 2(2), 120.

Velickova, E., Winkelhausen, E., Kuzmanova, S., Alves, V. D., \& Moldao-Martins, M. (2013). Impact of chitosan-beeswax edible coatings on the quality of fresh strawberries (Fragaria ananassa cv Camarosa) under commercial storage conditions. LWT - Food Science and Technology, 52(2, SI), 80-92. doi:10.1016/j.lwt.2013.02.004

Ventura-Aguilar, I. R., Bautista-Banos, S., Flores-Garcia, G., \& Zavaleta-Avejar, L. (2018). Impact of chitosan based edible coatings functionalized with natural compounds on Colletotrichum fragariae development and the quality of strawberries. Food Chemistry, 262, 142-149. doi:10. 1016/j.foodchem.2018.04.063

Verlee, A., Mincke, S., \& Stevens, C. V. (2017). Recent developments in antibacterial and antifungal chitosan and its deriva- 
Strawberries coated with fungal chitosan (gel, nanoparticles, gel + nanoparticles) | 393

tives. Carbohydrate Polymers, 164, 268283. doi:10.1016/j.carbpol.2017.02.001

Xing, K., Shen, X., Zhu, X., Ju, X., Miao, X., Tian, J., ... Qin, S. (2016). Synthesis and in vitro antifungal efficacy of oleoyl-chitosan nanoparticles against plant pathogenic fungi. International Journal of Biological Macromolecules, 82, 830-836. doi:10.1016/j.ijbiomac.2015.09.074

Yaman, O., \& Bayoindirli, L. (2002). Effects of an edible coating and cold storage on shelflife and quality of cherries. LWT - Food Science and Technology, 35(2), 146-150. doi:10.1006/fstl.2001.0827

Yen, M.-T., Yang, J.-H., \& Mau, J.-L. (2008). Antioxidant properties of chitosan from crab shells. Carbohydrate Polymers, 74 (4), 840-844.

Yien, L., Zin, N. M., Sarwar, A., \& Katas, H. (2012). Antifungal activity of chitosan nanoparticles and correlation with their physical properties. International journal of Biomaterials, 2012.

Yousuf, B., Qadri, O. S., \& Srivastava, A. K. (2018). Recent developments in shelf-life extension of fresh-cut fruits and vegetables by application of different edible coatings: A review. LWT - Food Science and Technology, 89, 198-209.

IJFS | October 2020 | Volume 9 | pages 373-393 